\title{
Acquired Coronary Cameral Fistula Due to Post Stent Balloon Dilatation: Dual Coronary Artery Perforations into the Left Ventricle- What Is the Right Treatment?
}

\author{
Avinash Murthy ${ }^{1}$, Arti Singh ${ }^{2}{ }^{*}$, Mitchell H. Driesman ${ }^{3}$ \\ ${ }^{1}$ Division of Cardiology, Department of Internal Medicine, Bridgeport Hospital, Bridgeport, CT, USA \\ ${ }^{2}$ Department of Internal Medicine, Bridgeport Hospital, Bridgeport, CT, USA \\ ${ }^{3}$ Cardiac Specialists PC, Fairfield, CT, USA \\ Email: ${ }^{*}$ artisingh2060@yahoo.com
}

Received 30 July 2014; revised 16 September 2014; accepted 1 October 2014

Copyright (C) 2014 by authors and Scientific Research Publishing Inc.

This work is licensed under the Creative Commons Attribution International License (CC BY). http://creativecommons.org/licenses/by/4.0/

c) (i) Open Access

\section{Abstract}

A fifty-year-old female with recent history of LAD stent placement for in-stent restenosis, presented with chest pain and ventricular fibrillatory arrest. Angiography revealed total occlusion of her LAD stent. She underwent IVUS study, balloon angioplasty and stent placements. Post balloon dilatation of the under-deployed distal stent resulted in dual coronary artery perforations with extravasation of contrast into the LV cavity, a Type 4 Ellis coronary artery perforation (CAP). No extravasation was noted into the pericardium. Immediately a covered stent was deployed which completely sealed both perforation sites with resultant TIMI grade 3 flow. Under-deployment of stents is a common occurrence and is underappreciated. It can happen due to various reasons. Not many options exist at that time but to use a high pressure balloon and post dilate the stent. One rare complication is CAP due to post stent dilatation, with incidence reported as $0.1 \%$ to $3.0 \%$ of PCI procedures. Among the various type of CAP, Ellis Type 4 is of the least frequent however no studies have looked at its exact incidence rate. Prompt recognition and quick intervention are essential to good patient outcome. We chose to deploy a covered stent over the perforation with interim balloon tamponading. Deployment of the stent successfully sealed both the CAPs. Remarkably the patient remained stable and did not complain of chest pain throughout the procedure. The patient did well; she was discharged on dual antiplatelet therapy and is continuing to do well. We report a rare case of 2 distal LAD perforations that drained into the LV (an Ellis Type 4 CAP) caused by post stent dilatation that were successfully treated with a single covered stent. We report successful management of this case along with review of literature about management and dilemmas encountered is such instances.

\footnotetext{
*Corresponding author.
}

How to cite this paper: Murthy, A., Singh, A. and Driesman, M.H. (2014) Acquired Coronary Cameral Fistula Due to Post Stent Balloon Dilatation: Dual Coronary Artery Perforations into the Left Ventricle-What Is the Right Treatment? World Journal of Cardiovascular Diseases, 4, 548-555. http://dx.doi.org/10.4236/wjcd.2014.411066 


\section{Keywords}

\section{Coronary Artery Perforation, Coronary Cameral Fistula, Ellis Type 4 Perforation, Covered Stent}

\section{Introduction}

The patient is a fifty-year-old female with a past medical history notable for congestive heart failure, hypertension and hyperlipidemia. In December of 2011, she sustained a myocardial infarction and received a $2.25 \times 26$ mm Integrity $(0.0889 \mathrm{~mm})$ Bare Metal Stent (BMS) to the mid Left Anterior Descending (LAD) artery for a 90\% stenotic lesion. In October of 2013, she presented with chest pain (CP) and underwent coronary angiography. It revealed in-stent restenosis along the entire length of the previously placed BMS. She was re-stented with a $2.25 \times 32 \mathrm{~mm}$ Promus Element $(0.081 \mathrm{~mm})$ drug eluting stent (DES) and was discharged on aspirin and prasugrel along with her other cardiac medications. Ten days later, she presented to the emergency department (ED) again with acute $\mathrm{CP}$ in the setting of non-compliance with prasugrel for the previous 3 - 4 days. In the ED she had a ventricular fibrillatory arrest and was resuscitated. Electrocardiography revealed ST elevation in the anterior-septal leads consistent with anterior wall myocardial infarction (MI) (Figure 1). She was brought emergently to the cardiac catheterization lab where angiography confirmed a total occlusion at the site of the LAD stent (Figure 2). After aspiration thrombectomy, an intravascular ultrasound study (IVUS) revealed underdeployment of the LAD stent (Figure 3) with residual disease proximal and distal to the stent. She underwent balloon dilatation of the underdeployed stent. A new $2.25 \times 26 \mathrm{~mm}$ Resolute $(0.0889 \mathrm{~mm})$ DES was deployed distally at 8 atmospheres (atm) in an overlapping fashion with the overlapping area post dilated at 12 atmospheres. A Resolute $3.0 \times 18 \mathrm{~mm}$ DES was deployed proximally overlapping the proximal Integrity BMS and the Promus Element DES stent. Repeat angiography revealed underexpansion of the distal stent, and the patient underwent another high-pressure balloon inflation of the distal stent with the $3.0 \mathrm{~mm}$ stent balloon. Follow up angiography revealed two coronary perforations at the overlap region of the previously placed Integrity, Promus, and proximal aspect of the newly deployed distal Resolute stent with extravasation of contrast into the LV cavity (Figure 4, Figure 5). No extravasation of contrast was noted in the pericardial space. A diagnosis of a Type 4 (also known as Cavity Spilling) Ellis coronary artery perforation (CAP) was made. Immediately the $3.0 \mathrm{~mm}$ stent balloon was deployed to impede any free leak of blood (Figure 6). Emergent bedside echocardiography did not reveal any pericardial effusion. With the intracoronary balloon in place, contralateral access was obtained

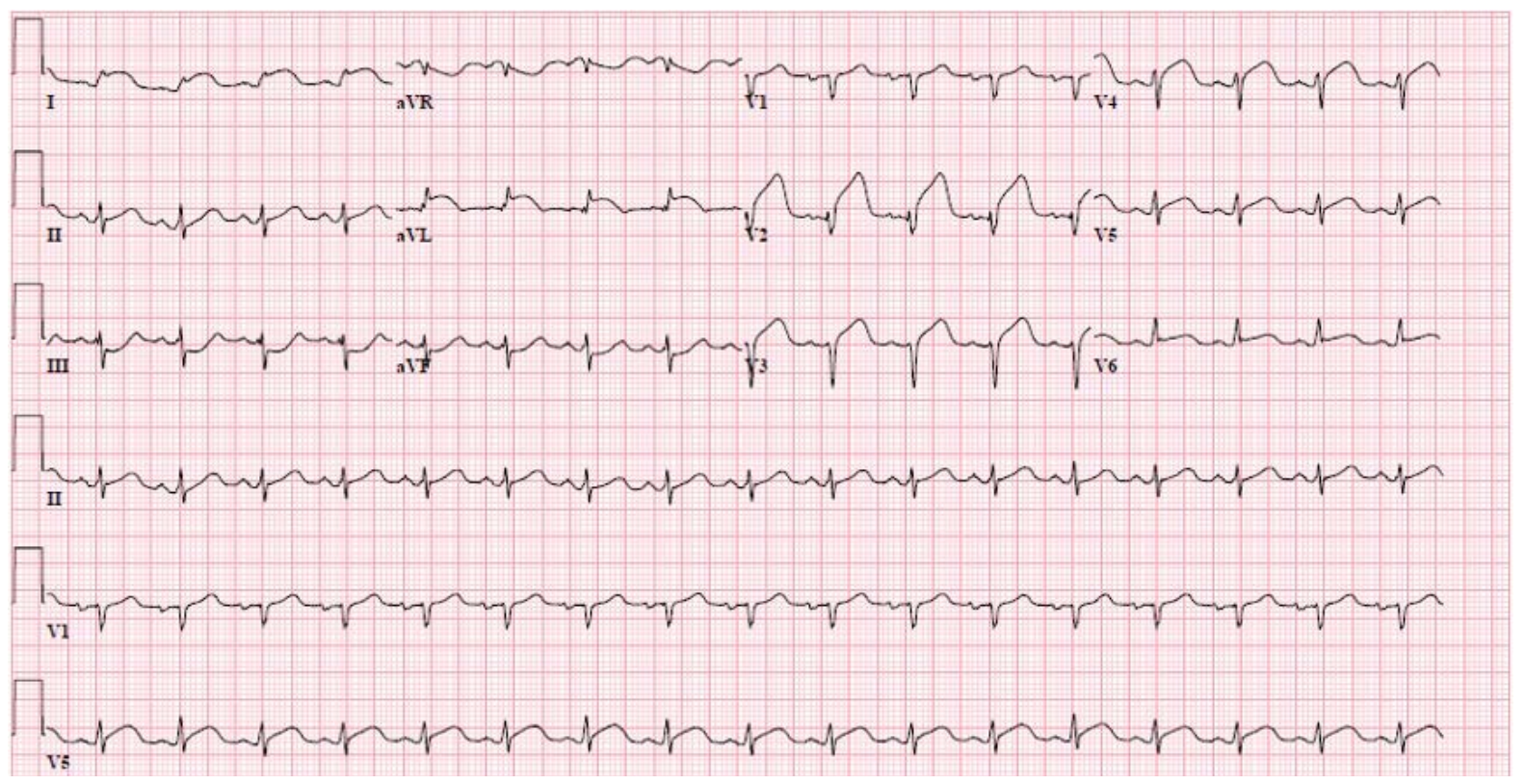

Figure 1. Electrocardiogram, showing ST segment elevations consistent with anterior wall infarction. 


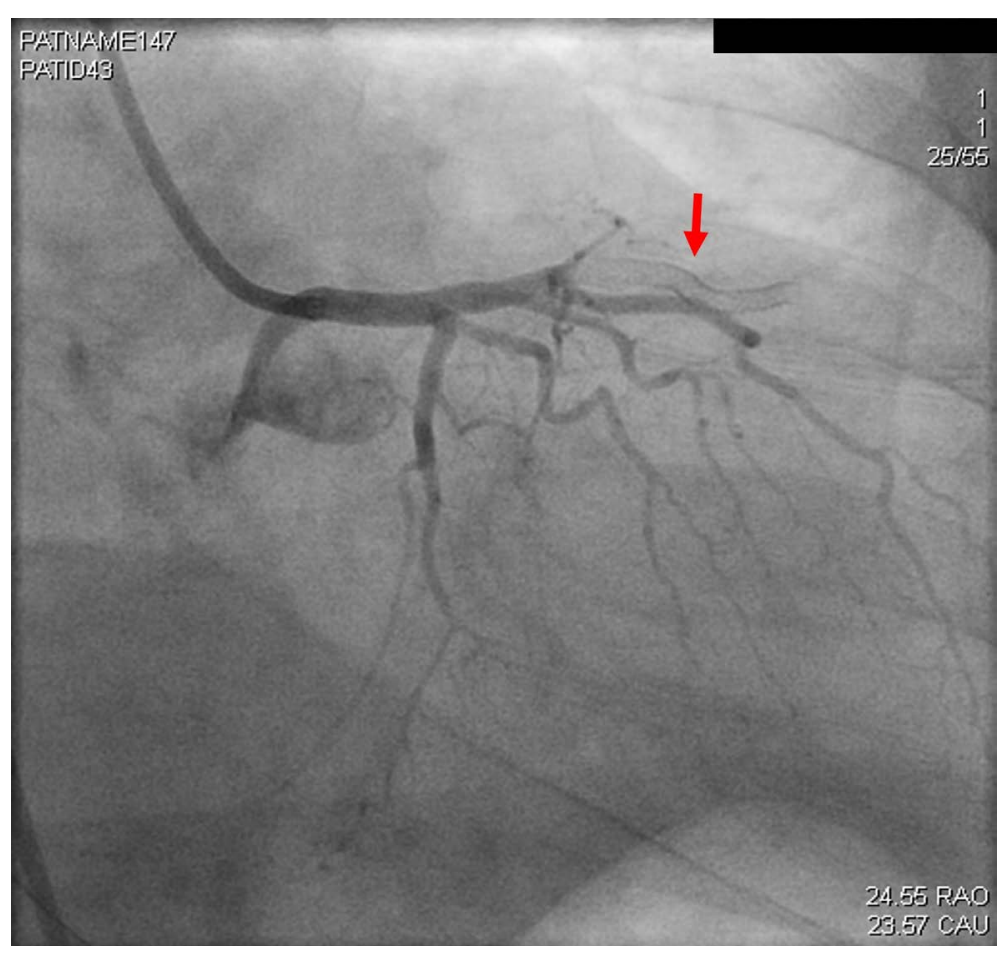

Figure 2. Coronary angiography, RAO view, showing total occlusion of the left anterior descending artery.

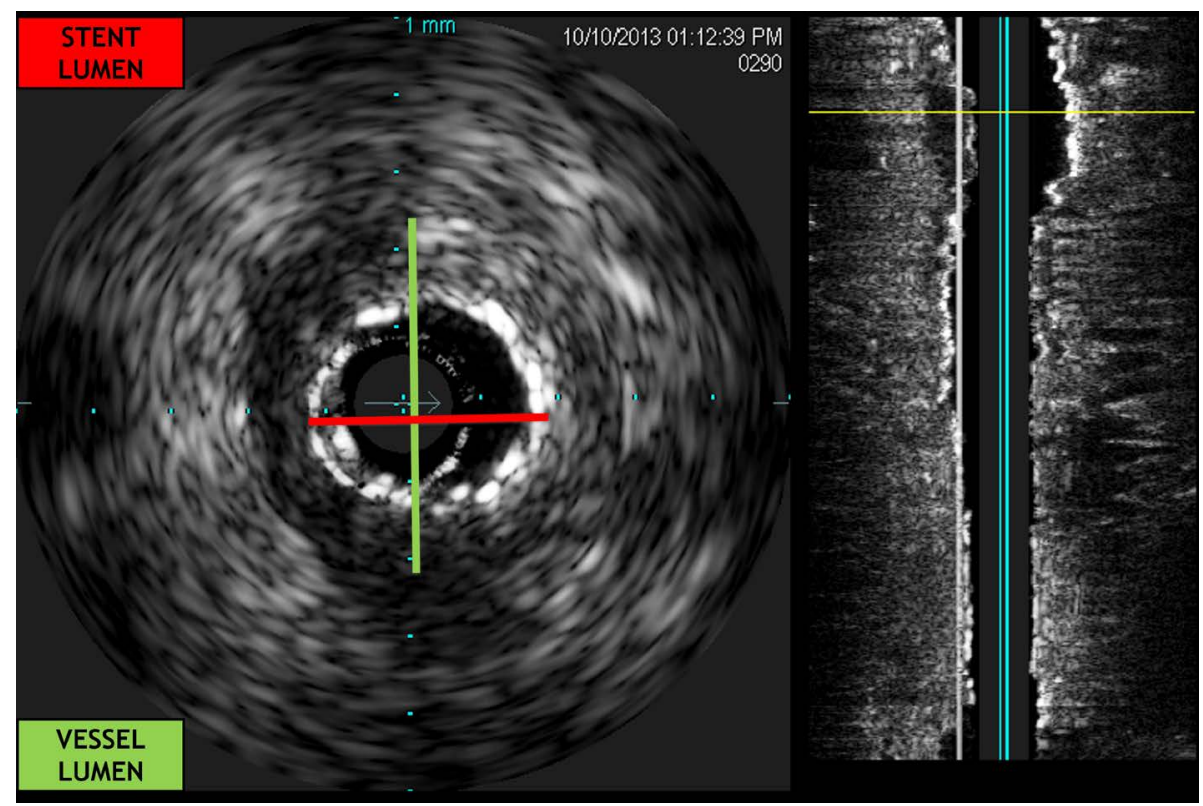

Figure 3. Intravascular ultrasound (IVUS) showing under-deployment of previous stent.

and another coronary guide was used to simultaneously engage the left coronary artery. A second 0.014 " coronary wire was placed distal to the perforations, with the continuous balloon tamponade interrupted only transiently to allow wire passage. A $3.0 \times 19 \mathrm{~mm}$ Jomed covered stent was rapidly deployed in a "quick replacement" manner. The two perforations were completely sealed, with resultant TIMI grade 3 flow confirmed on angiography (Figure 7). Her remaining hospital course was uneventful and she was discharged on the $10^{\text {th }}$ day of her hospitalization. She has been asymptomatic since discharge. 


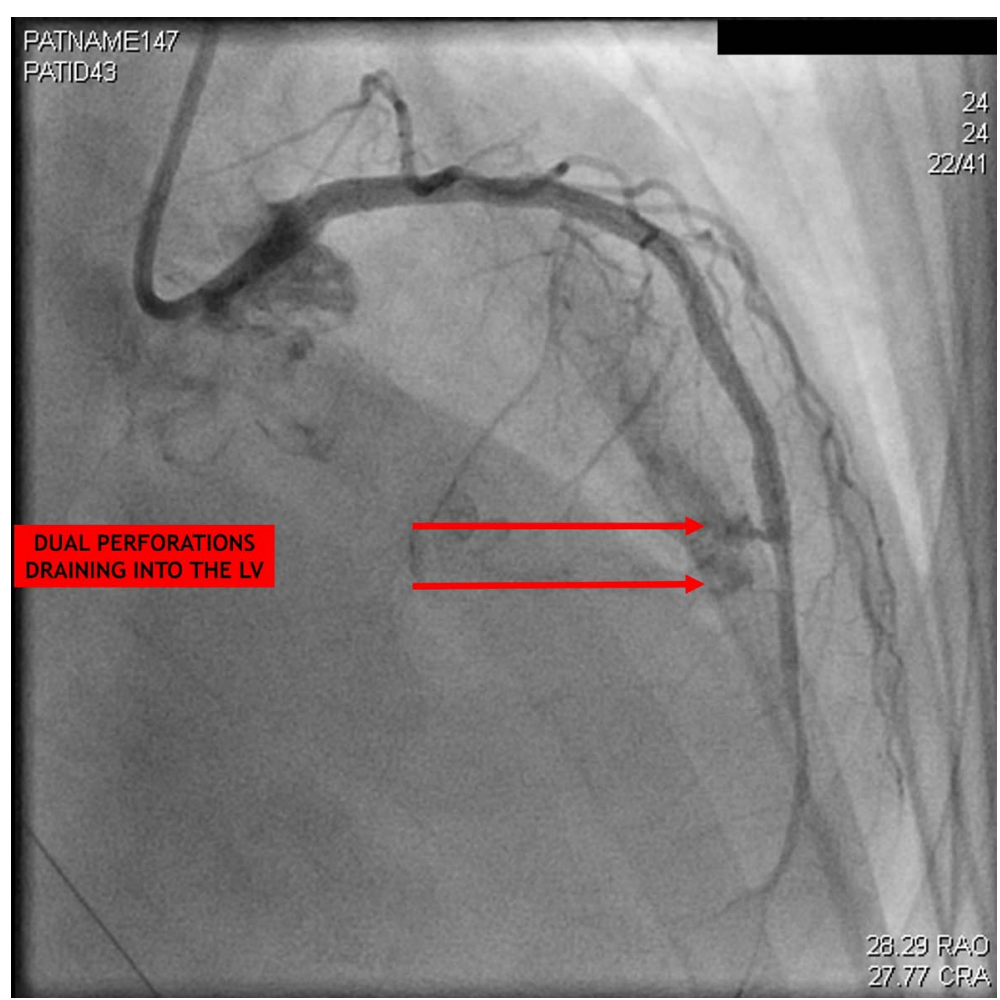

Figure 4. Coronary angiography, RAO view, showing coronary artery perforation with extravasation of contrast into the Left Ventricular Cavity. No contrast is noted in the pericardium.

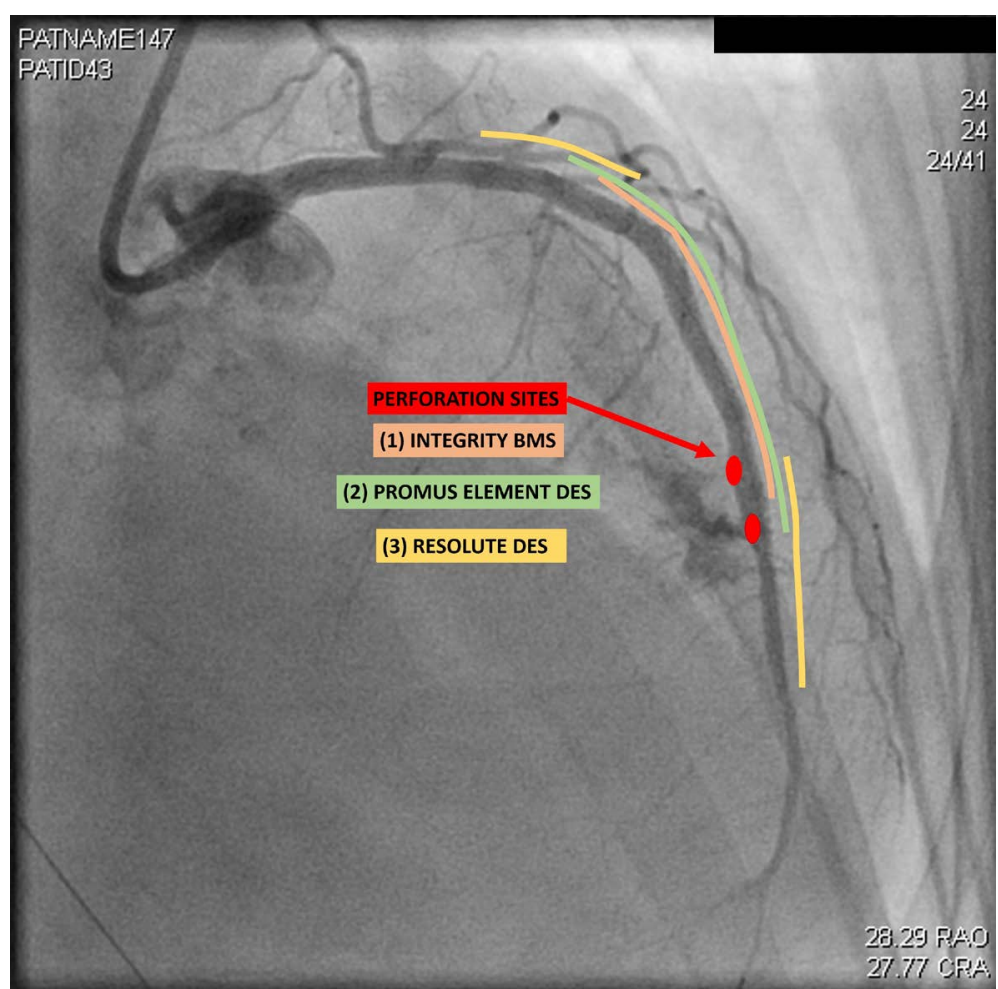

Figure 5. Cartoon showing the Left Anterior Descending Artery with the "triple strut sandwich”. 


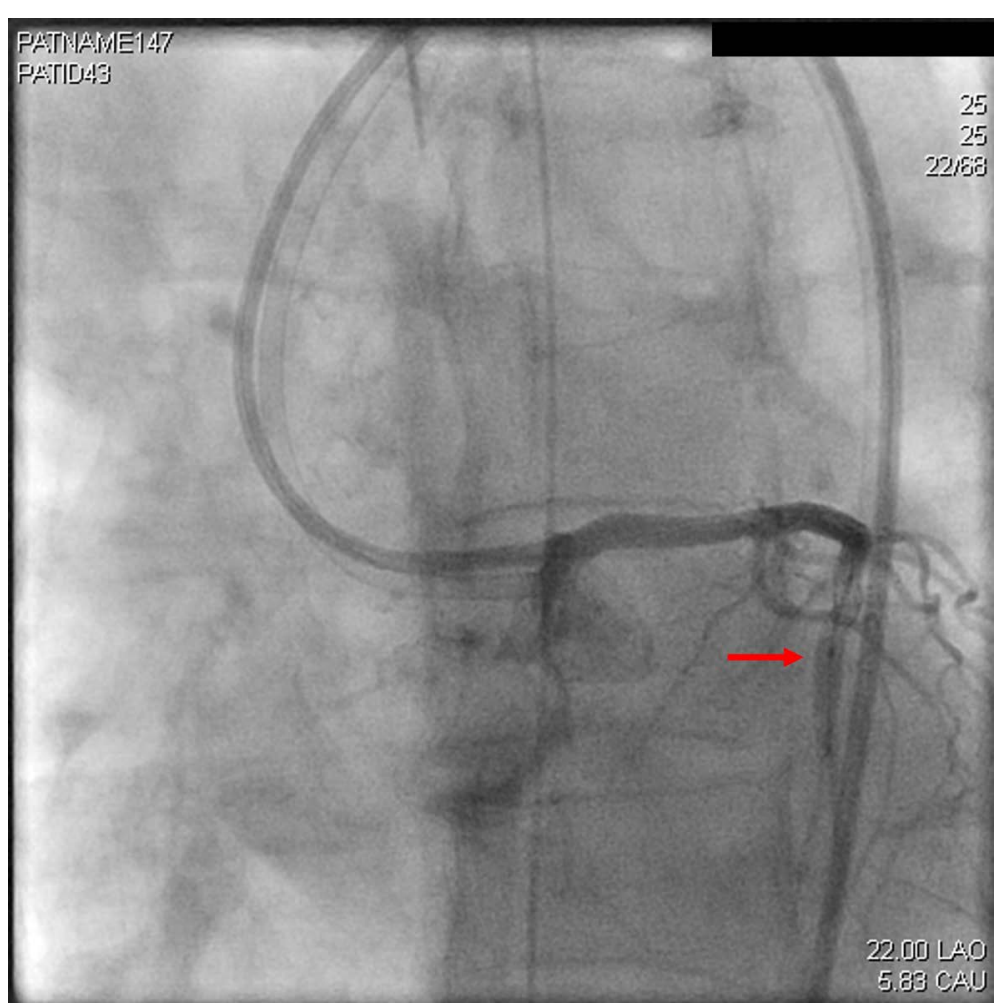

Figure 6. Coronary angiography, LAO view, showing successful tamponading of the perforation with stent balloon.

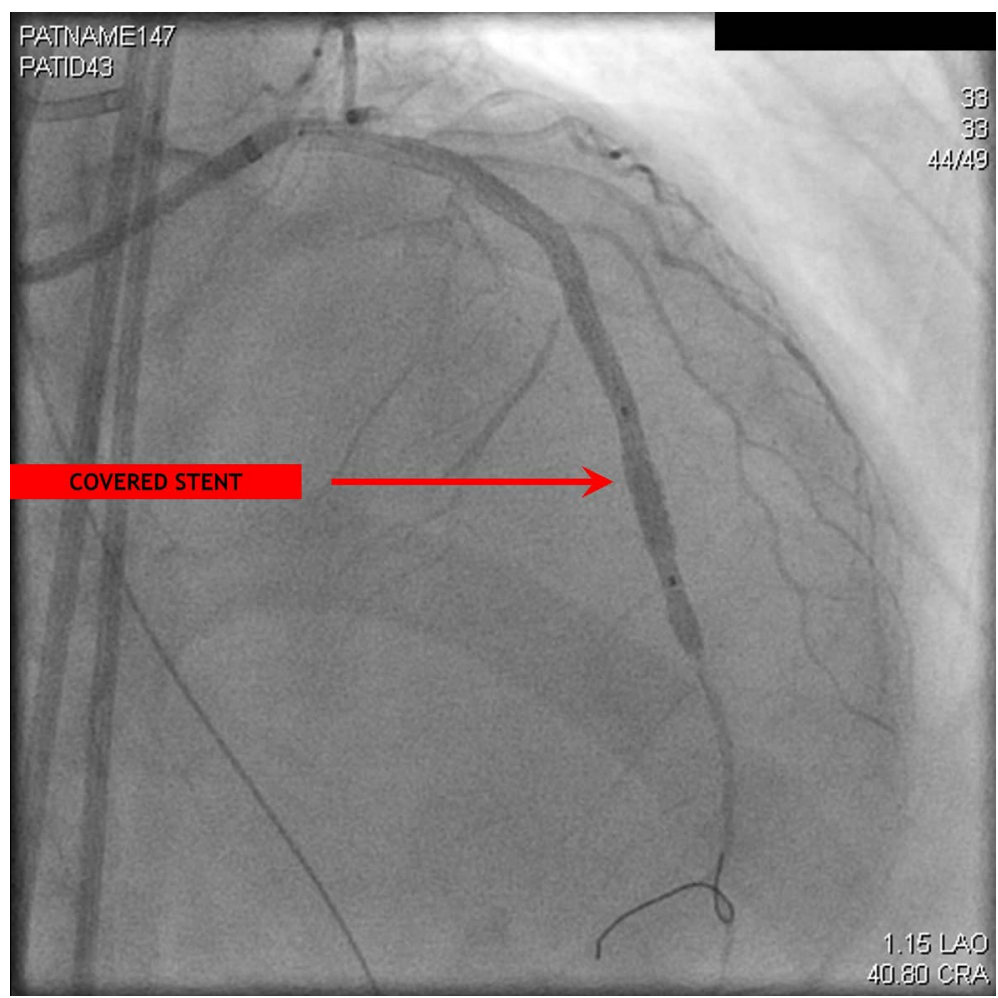

Figure 7. Coronary angiography, LAO view, showing successful placement of covered stent covering the coronary artery perforation. 


\section{Discussion}

Coronary artery perforation (CAP) during angioplasty is rare with an estimated incidence of 0.19\% to 0.59\% [1]. Review of the literature cites a number of predisposing risk factors including advanced age, female gender, hypertension, hyperlipidemia, diabetes, chronic renal failure, history of prior coronary artery bypass graft (CABG), heavy coronary artery calcification, chronic total occlusion, tortuous vessels, target lesions in the circumflex and right coronary arteries, long target lesions $(>10 \mathrm{~mm})$, eccentric lesions, and small vessel size amongst others [2]. During percutaneous coronary intervention (PCI), coronary artery perforation may occur as a consequence of hydrophilic or extra stiff guide wire advancement, excessive over-dilation of a stent under high pressure or use of an oversized stent with high-pressure balloons, use of an atheroablative device, laser angioplasty, or IVUS catheter use for PCI optimization [1].

According to Ellis et al., the diagnosis and classification of coronary artery perforation is based on the angiographic appearance of the perforation [3]. If the perforation is limited to the vessel wall (i.e., produces an intramural crater without extravasation on the angiogram) it is diagnosed as an Ellis Type 1 CAP, and has a benign prognosis [2]. Ellis Type 2 CAP has limited extravasation with pericardial or myocardial blushing on angiography. The perforation size is generally less than $1 \mathrm{~mm}$ in diameter, and because there is extravasation into the pericardial space, Ellis Type 2 perforations have the potential to progress to tamponade [1]. Ellis Type 3 perforations result in prominent streaming of contrast into the pericardial space and the exit hole is generally greater than $1 \mathrm{~mm}$ [2]. Type 3 lesions are associated with hemodynamic instability, and nearly 50\% of the cases lead to cardiac tamponade requiring pericardial drainage [1]. Some of the Type 3 CAP were noted to be spilling into an anatomic cavity, and thus these perforation types were referred to as “Cavity Spilling” by Ellis et al. Some authors have listed these Cavity Spilling perforations as Ellis Type 4 [4]. In Type 4 or Cavity Spilling CAP, the contrast flows into a cardiac chamber such as the LV or a coronary sinus rather than into the pericardial space or myocardium [2]. Among the various types of CAP, Ellis Type 1 lesions have the most benign prognosis, while Ellis Type 3 lesions have the potential for the worst prognosis. Ellis Type 4/Cavity Spilling types of perforations are the least frequent; no studies have looked at its exact specific incidence rate or overall prognosis. A recent report by Meguro et al., analyzed 3469 PCIs, and found 30 CAP (overall incidence of 0.86\%), and of these 30 cases, 17 cases were of Type I CAP, two cases of type II CAP, and 11 type III CAP cases. However a distinction between Type 3 perforation and Cavity Spilling perforation was not made. In the study, most cases of Type 1 CAP were causes by wires/balloons, while Type 3 CAP were mostly due to stents. Most cases of stent CAP were successfully managed with prolonged balloon inflations with one third requiring CABG [5]. Another study by Aykan et al., analyzed 12,784 PCIs retrospectively, and 25 CAP were found (overall incidence of 0.02\%), and of these 25 cases, 14 patients had ACS (6 STEMI, 8 NSTEMI). Type 1 CAP was found in 8 of 25 patients (32\%), Type 2 in 6 (24\%) patients, and Type 3 in 11 (44\%) patients. Again a distinction between Type 3 and Cavity Spilling perforation was not made. Emergent CABG was required in 2 patients with Type 3 CAP, and there were no in-hospital mortality in the 25 patients. The study concludes that outcomes or near-term prognosis of CAP in patients with ACS were similar to patients with stable coronary disease [6]. However, to our knowledge, there have been no recent studies that have looked at iatrogenic CAP long-term prognosis.

Coronary artery perforations are generally managed with covered stents and reversal of anticoagulation with success rates reported in the literature of greater than 90\% [7]. Ellis Type 1 and 2 perforations can be treated with prolonged balloon inflation, which is best done with a perfusion balloon catheter [1]. In general, covered stents are ideal for proximal or mid-segment perforations. BMS with narrow struts can be used for distal lesions [7]. Coronary artery perforations can also be treated with various embolization materials such as metal coils, collagen, glue, thrombogenic particles such as polyvinyl alcohol, gelfoam, thrombin, or N-butyl cyanoacrylate glue. Surgery, given the high success rate of PCI is often considered as a last resort. Surgical options include operative repair with ligation or suturing of the perforated vessel, placement of a bypass graft to the distal vessel, pericardial patch or Teflon felt wrapping repair [1].

When "cavity spilling” types of perforations or coronary cameral fistulas are encountered the treatment options are unclear. Since the perforation is not spilling into the pericardial space, it is considered an artery-artery fistula. Questions arise whether it is necessary to intervene emergently. Considering that covered stents have high occlusion rates, BMS stents have high restenosis rates and embolization results in downstream infarct, the best possible treatment choice is difficult. Previous studies in coronary cameral fistulas have revealed that traumatic coronary artery-cameral fistulas (TCAF) resulting from penetrating cardiac trauma are highly lethal, and 
require early surgical intervention [8]. In comparison, iatrogenic traumatic acquired coronary artery cameral fistulas (CCF) (such as those from stent placement in a chronic total occluded vessel) and spontaneously acquired CCF (which develop post-MI) have low flow, and can be treated with supportive medical management [9]. There have been case reports of spontaneous closure of cavity spilling perforation after PCI [8] [9]. Therefore it seems reasonable to treat large and moderate sized coronary perforations into the left ventricle while reserving a conservative strategy for smaller ones. There are no standard management recommendations, and therapy should be tailored according to the clinical context and patient stability.

The IVUS study in the current case revealed an under-deployed stent, which is a common and underappreciated occurrence. In such instances, not many options exist but to use a high-pressure balloon to dilate the stent. One rare complication of high-pressure stent strut dilation is CAP with incidence reported as $0.1 \%$ to $3.0 \%$ of PCI procedures. Stenting causes vessel wall injury, the extent of which is determined by the number of stent struts involving a vessel lumen, and the degree of stent strut dilation (i.e., hence the anatomic depth at which the stent struts penetrate the vessel wall). Balloon expansion advances the strut through the internal elastic lamina, then the media, external elastic lamina, and finally adventia [10]. In humans stent struts account only for $32 \%$ of direct medial injury as most struts are in contact with atheromatous plaque and not the media [11].

The current era stent struts are relatively thin with the diameter varying between $0.0032-0.0035$ inches (with Resolute DES at $0.0889 \mathrm{~mm}(0.0035$ ”), PROMUS Element DES at $0.081 \mathrm{~mm}(0.0032$ ”), Integrity BMS at $0.0889 \mathrm{~mm}(0.0035$ ”)). In our patient, the combined thickness of three overlapping stents is $0.2659 \mathrm{~mm}(0.0889$, $0.0889,0.0881$ ) or greater than a quarter of a one millimeter. When deployed under high pressure one could readily hypothesize a predilection to stent perforation. Post stent dilation of this triple "stent sandwich" may have resulted in expansion of the overlapping stent struts against acutely inflamed myocardium causing a cavity spilling type of perforation.

With the CAP draining to the LV alone, there was no need for emergent pericardiocentesis, thus allowing for execution of a well thought out management plan. We chose to deploy a covered stent over the perforation with interim balloon tamponading. Deployment of the single stent successfully sealed both perforation sites. The patient remained stable and did not complain of chest pain throughout the procedure.

\section{Follow-Up}

The patient did well post procedure, and was discharged on dual antiplatelet therapy. She is continuing to do well. This, to our knowledge, is the first reported case of an acquired coronary cameral fistula due to post stent dilatation.

This case is thought provoking as it outlines current options for CAP treatment, discusses some of the challenges in its management, and additionally highlighting the dangers of high pressure balloon dilation when there are multiple overlapping stents. There are no standard management guidelines in such instances and therapy must be customized. Severe complications associated with CAP reinforce the necessity for interventionists to take measures to minimize risks. Awareness of risk factors with careful guidewire and balloon size selection, and avoidance of stent overexpansion is vital to CAP prevention.

\section{Disclosure Statement}

The authors report no financial relationships or conflicts of interest regarding the content herein.

\section{Acknowledgements}

Lawrence S. Cohen, MD. The Ebenezer K. Hunt Professor of Medicine (Emeritus). Yale University School of Medicine, New Haven, CT. We thank Dr. Cohen for his guidance and editing.

\section{References}

[1] Al-Mukhaini, M., Panduranga, P. and Sulaiman, K. (2011) Coronary Perforation and Covered Stents: An Update and Review. Heart Views, 2, 63-70.

[2] Kilic, I., Alihanoglu, Y., Yildiz, S., et al. (2013) Coronary Artery Perforations: Four Different Cases and a Review. Portuguese Journal of Cardiology, 10, 811-815.

[3] Ellis, S.G., Ajluni, S., Arnold, A.Z., et al. (1994) Increased Coronary Perforation in the New Device Era. Incidence, 
Classification, Management and Outcome. Circulation, 90, 2725-2730. http://dx.doi.org/10.1161/01.CIR.90.6.2725

[4] Shimony, A., Joseph, L., Mottillo, S. and Eisenberg M. (2011) Coronary Artery Perforation during Percutaneous Coronary Intervention: A Systematic Review and Meta-Analysis. Canadian Journal of Cardiology, 27, 843-850. http://dx.doi.org/10.1016/j.cjca.2011.04.014

[5] Meguro, K., Ohira, H., Nishikido, T., et al. (2013) Outcome of Prolonged Balloon Inflation for the Management of Coronary Perforation. Journal of Cardiology, 61, 206-209. http://dx.doi.org/10.1016/j.jjcc.2012.11.007

[6] Aykan, A.C., Guler, A., Gul, I., et al. (2014) Management and Outcomes of Coronary Artery Perforations during Percutaneous Treatment of Acute Coronary Syndromes. Perfusion, 1-6.

[7] Karabulut, A. and Topcu, K. (2011) Coronary Perforation Due to Sirolimus-Eluting Stent's Strut Rupture with PostDilatation. Kardiologia Polska, 2, 183-186.

[8] Sheikhi, M., Asgari, M. and Firouzabadi, M. (2011) Traumatic Left Anterior Descending Coronary Artery-Right Ventricle Fistula: A Case Report. The Journal of Tehran University Heart Center, 2, 92-94.

[9] Said, S., Schiphorst, R. and Derksen, R. (2013) Coronary-Cameral Fistulas in Adults: Acquired Types (Second of Two Parts). World Journal of Gastroenterology, 12, 484-494.

[10] Lowe, H., Oesterle, S. and Khachigian, L. (2002) Coronary In-Stent Restenosis: Current Status and Future Strategies. JACC, 2, 183-192. http://dx.doi.org/10.1016/S0735-1097(01)01742-9

[11] Farb, A., Sangiorgi, G., Carter, A.J., et al. (1999) Pathology of Acute and Chronic Coronary Stenting in Humans. Circulation, 99, 44-52. http://dx.doi.org/10.1161/01.CIR.99.1.44 
Scientific Research Publishing (SCIRP) is one of the largest Open Access journal publishers. It is currently publishing more than 200 open access, online, peer-reviewed journals covering a wide range of academic disciplines. SCIRP serves the worldwide academic communities and contributes to the progress and application of science with its publication.

Other selected journals from SCIRP are listed as below. Submit your manuscript to us via either submit@scirp.org or Online Submission Portal.
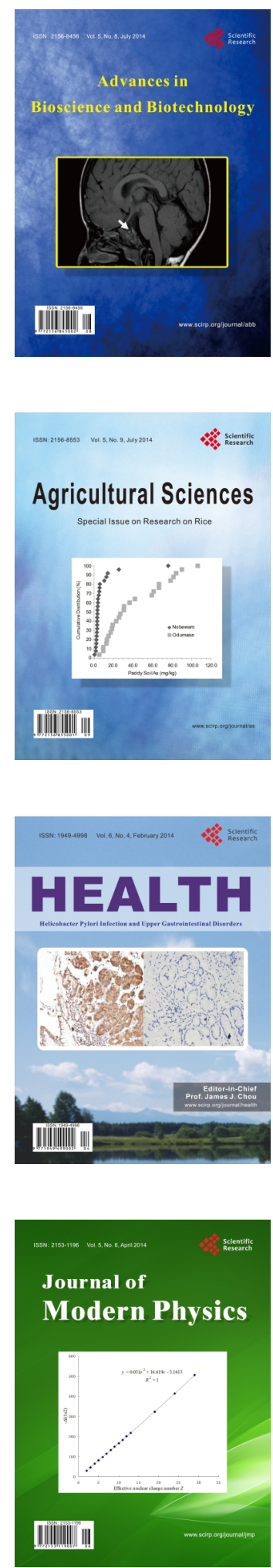
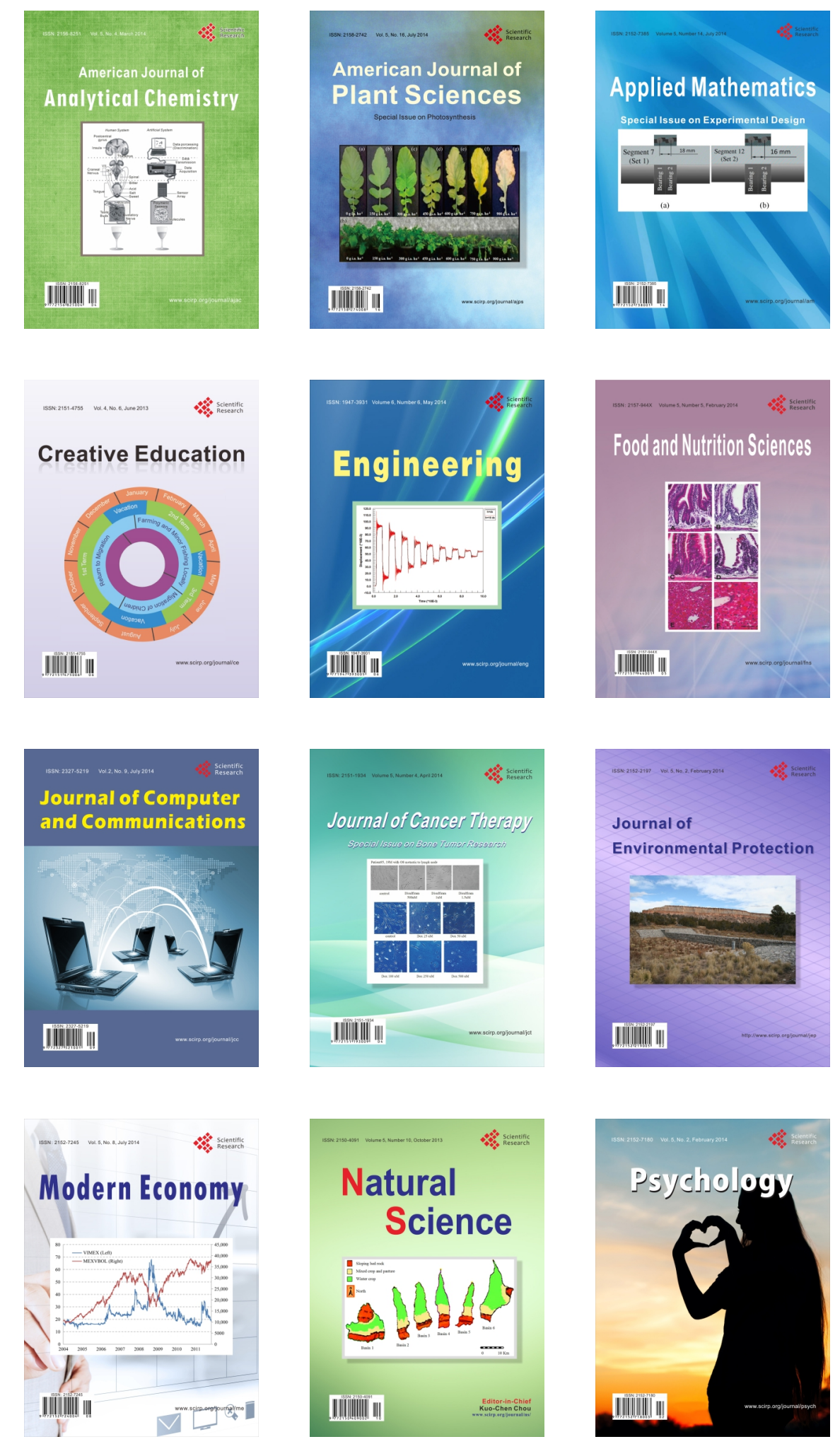